\title{
Effective earthing system of electrical power engineering department using optimal electrodes
}

\author{
Su Mon Myint ${ }^{{ }^{*}}$, Khin Thidar Hla ${ }^{2}$ and Theint Theint Tun ${ }^{2}$ \\ Lecturer, Department of Electrical Power Engineering, Pyay Technological University, Myanmar ${ }^{1}$ \\ Assistant Lecturer, Department of Electrical Power Engineering, Pyay Technological University, Myanmar ${ }^{2}$
}

Received: 27-December-2019; Revised: 18-February-2020; Accepted: 21-February-2020

(C)2020 Su Mon Myint et al. This is an open access article distributed under the Creative Commons Attribution (CC BY) License, which permits unrestricted use, distribution, and reproduction in any medium, provided the original work is properly cited.

\begin{abstract}
Some of the buildings in Myanmar are not provided with a reliable earthing system for protection against electric shock. Thus, residents, equipment around this environment may experience the electrocution under fault conditions that often occur in the rainy season among three seasons. Soil resistivity completely influences on the making of the earthing system. When the economical and effective earthing system creates, location of the area must be the lowest soil resistivity. In this research, electrical power engineering department in Pyay city, one storey reinforced cement concrete building, is chosen for the earthing system. Neutral earthing system of the power supply source and building's installation earthing system is considered. Three conditions for the reduction of earthing resistance value by changing the three variables of earth electrode. A mixture of clay and sand soil is selected as a uniform soil resistivity for both earthing systems. The vertical earth rod is exploited as an electrode to carry and drive the fault current to the earth. Copper rod is elected because of less corrosion and more conductivity than any other materials. The terre-terre (TT) earthing system is applied as an earthing method and parallel configuration is used for multiple electrodes in rectangular shape for six rods and equilateral triangle shape for three rods to achieve the acceptable earth resistance according to IEEE 142 and BS 7430. Results of earth resistance on the variant forms of diameter, length and numbers of earth rods and minimum earth conductor size are revealed for supply transformer and building earthing system.
\end{abstract}

\section{Keywords}

Earthing system, Soil resistivity, Earth rod, Parallel configuration, Earth resistance.

\section{Introduction}

Earthing is the most important part of an electrical installation that is used to divert high currents to the earth during normal and fault conditions. Department of electrical power engineering department is chosen as a case study because it has office room and practical lab for first year students. The objectives of this research are to prevent from electric shock for creating a reliable environment and workplace that student and staffs perform safely their work and to have an effective earthing system at the department. At the time of the fault, current from the equipment flows through the earth grid of the earth and then protect them from the fault current. The earth mat conductors rise in the voltage which is equal to the multiplication of earthing resistance of the earth mat and ground fault current. The assembly of contacts is defined as earthing.

*Author for correspondence
Electrical connection means the metallic conductors linking the parts of the installation with the earthing. Thus, earthing system is defined as the combination of the earthing and earthing connection together. Earthing systems are essentially needed for power generating substations, central offices, and communication tower sites.

According to the earthing of two non-current carrying parts of the electrical system, earthing can be categorized into neutral earthing and equipment earthing. In the former earthing, the neutral of the system which has star winding is directly affixed to the earth by using the Galvanised Iron wire. This earthing is also specified the system earthing that is established in the generator, transformer, motor etc. The latter earthing is set up with the electrical equipment. If any fault occurs in the apparatus, the fault current will flow to the earth with the help of wire. Earthing can be provided by electrically joining the respective elements in the installation to some system of electrical conductors or electrodes that are 
placed near the soil or below the ground level. In order to protect people, the current through human body has to be kept lower than certain values. Whereas in the earthing design of building and industries, touch and step voltage calculation are not carried out. The total earth grid resistance has to be maintained below certain prescribed value [1].

In electrical installation, earthing system is important for safety. The building should be installed with good protection that needs an effective earthing system. In buildings and industries, rise in potential is due to the flow of fault current through the earth. All over the world may be considered as a vast conductor which is at the reference (zero) potential. The earthing system of any installation needs to be designed to handle all such faults effectively. Four factors affect the earth resistance of an earthing system. They are earth electrode's length, electrode's diameter, numbers of electrodes and earth grid design. If the soil resistivity is high, the penetration of the charges into the earth mass would be low. Soil leads to varying its resistivity and cannot be estimated. So, soils may be classified by applying the soil test. The value of resistance can generally be decreased by doubling the length of the earth electrode. Very effective way to be lower earth resistance is driving earth electrodes deeply. And, very little effect in decreasing the resistance by increasing the diameter of the earth electrode. Besides, the resistance level can be lessened by hitting multiple electrodes with parallel connection into the ground. Using multiple earth electrodes with suitable earth mat design provides another way to lessen earth resistance. To be effective for additional earth rods, the distance of these rods must be at least equal to the length of a driven earth rod. A single earth electrode driven into the ground is a simple earthing system that is the most common form of earthing. Earthing system with multiple earth rods, connected to grid networks, ground plates, and ground loops is called the complex earthing system. The shapes of the earth grid design are mostly generally found in a line, rectangular, circular, square, triangular and star. Common forms of earth electrode are plate, rod or pipe and strip type. Materials of electrode are mostly copper, aluminium and galvanised iron, etc. [2]. Among them, solid copper vertical rod for multiple electrodes is driven by the parallel connection to earth in this research.

\section{Literature review of earthing system}

Oyeleye [3] stated that evaluation of substation's transformer, earthing system, feeder panel and lightning grounding of a university in Nigeria to prevent from equipment damages, equipment malfunctioning, electric shock and electrocution of life. For testing an earth electrode system, fall-ofpotential method and clamp-on method are applied. Virendra et al. [4] aimed that earthing system design for electrical installations of building construction and laboratory equipment to save human life from danger of electrical shock, to provide an alternative path for the fault current to flow so that it will not endanger the user, to protect buildings, machinery and appliances under fault conditions. Fall of potential technique is used in a testing of earth resistance. By using good conducting property earthing electrode and soil preparation can decrease the earth resistance that is also recommended. Oyeleye and Makanju [5] presented that evaluation of steel reinforcement earthing in swamp building of Federal University of Technology Akure in Nigeria by using kyoritsu digital earth tester to establish the safe limit of potential difference and to operate without injury to personnel and equipment. Swamp is very wet land with a layer of water. The wetter the soil, the lesser its resistance as the soil resistivity is directly proportional to earth resistance. Ayodele et al. [6] proposed the comparative assessments of four earthing grid system configurations such as triangular, rectangular, $\mathrm{T}$ and $\mathrm{L}$ shape using IEEE and finite element methods to determine the best earthing grid configuration in terms of earthing grid resistance, ground potential rise, touch voltage and step voltage for a typical food and beverages industry in Nigeria. Michaels [7] member of IEEE, submitted that the Equipment Grounding System (EGS) as an effective bonding topology for telecommunications environments to search feasible options in providing an equipotential plane for alternate telecommunications bonding infrastructure and to obtain the same effect as the standard practices in place today. Talaat et al. [8] specified the simulation of the electric field and the Ground Potential Rise (GPR) resulting from vertical driven rods earthing system in a multilayer earth structure that protects human beings from harm and reduce damage to electrical power system equipment by exploiting finite element method, charge simulation method and COMSOL Multiphysics software with different types of earth models.

Earthing grid designs for heterogeneous soil structures in hilly regions using current simulation method is reported by Mondal et al. [9] In this research, values for grid resistance, step and mesh voltage of the grid designs on multilayer and heterogeneous soil in hilly region by applying current 
simulation method. Wang et al. [10] Pan revealed an improved method for measuring grounding resistance of transport tower that intend to flow the lightning current to the earth through the tower grounding device based on principle of the clamp meter method when a tower has a lightning strike. Maier et al. [11] Pica wrote optimal design of vertical earth grounding with a rectangular perimeter that intends to allocate vertical electrodes for a rectangular configuration on two aspects such as dispersion surface area and investment cost of earth grounding element with considering the connection of conductors between electrodes. The higher length of electrodes, the lower values of earth resistances and the deduction of the distance between electrodes, the lesser the investment costs are also described. Maier et al. [12] explained methodologies regarding the application of optimum criteria to the vertical earth grounding design with a rectangular outline to achieve the minimum spacing between grounding rods and optimal sizing of vertical ground rods based on two criteria such as grounding area and grounding total volume. In the research journal of safety performance evaluation of typical grounding configurations of $\mathrm{MV} / \mathrm{LV}$ distribution substations by Datsios et al. [13] safety operation against the danger of critical electric shock due to touch and step voltages resulting in case of a ground fault. Soil from multilayers impacts on soil resistivity, ground potential rise, step and touch voltage that are carried out by CYMGrd software for 20/0.4 kV distribution substation.

\section{Methodology}

In this research, copper earth rods are selected to drive into the ground that are connected in parallel configuration and mixture of clay and soil is chosen as a sample of soil according to standard penetration test (SPT). Besides, copper hard drawn wire is used for the connection of earth rods. Source side is a distribution transformer and a building are considered as a load side. Terre-terre (TT) earthing system is a simple construction that has one or more points of energy source directly earthed and the exposed and extraneous conductive sections of the building's installation are joined to the local earth electrodes that are electrically independent on the source earth. The required mathematical equations for evaluating of earth resistance for a single rod, multiple earth rods and minimum conductor size are illustrated in the following equations. Cable factor $(\mathrm{K})$ is used in cable sizing that vary in conductive materials. Required equations and reference tables are applied from BS 7430 code for electrical equipment earthing and IEEE 142 for supply system earthing. (i) For electrical equipment earthing,

For a single earth rod,

$$
\mathrm{R}=\frac{\rho}{2 \times \pi \times \mathrm{L}}\left[\log _{\mathrm{e}}\left(\frac{8 \times \mathrm{L}}{\mathrm{d}}\right)-1\right]
$$

where,

$\rho=$ Resistivity of the soil $(\Omega \mathrm{m})$

$\mathrm{L}=$ Length of the electrode $(\mathrm{m})$

$\mathrm{d}=$ Diameter of the electrode $(\mathrm{m})$

For multiple earth rods,

$$
\mathrm{R}_{\mathrm{n}}=\mathrm{R}\left[\frac{1+\lambda \mathrm{a}}{\mathrm{n}}\right]
$$

Factor, $\mathrm{a}=\frac{\rho}{2 \times \pi \times \mathrm{R} \times \mathrm{s}}$

where,

$\mathrm{R}=$ Resistance of a single $\operatorname{rod}(\Omega)$

$\mathrm{n}=$ Number of electrodes

$\rho=$ Resistivity of the soil $(\Omega \mathrm{m})$

$\mathrm{a}=$ Spacing factor $(\mathrm{m})$

$\mathrm{s}=$ Spacing between adjacent rods $(\mathrm{m})$

$\lambda=$ Multiplying factor for parallel electrodes [14]

(ii) For supply system earthing

Fullload current, $\mathrm{I}_{\mathrm{fl}}=\frac{\mathrm{S}}{\sqrt{3} \times \mathrm{V}_{\mathrm{L}}}$

Fault current, $\mathrm{I}_{\mathrm{f}}=\frac{100}{\% \mathrm{Z}} \times \mathrm{I}_{\mathrm{fl}}$

Conductor cross - sectional area, $A=\frac{I_{f} \times \sqrt{t}}{K}(6)$

$\mathrm{P}=\sqrt{3} \times \mathrm{V}_{\mathrm{L}} \times \mathrm{I}_{\mathrm{L}} \times \cos \theta$

Maximum permissible current,$I=\frac{34800 \times d \times L}{\sqrt{\rho \times t}}$

Number of electrode, $\mathrm{N}=\frac{\mathrm{I}_{\mathrm{f}}}{\mathrm{I}}$

$\mathrm{R}_{\mathrm{n}}=\mathrm{R} \times \frac{\mathrm{F}}{\mathrm{N}}$

where,

$\mathrm{S}=$ Apparent power $(\mathrm{kVA})$

$\mathrm{I}_{\mathrm{fl}}=$ Full load current (A)

$\mathrm{V}_{\mathrm{L}}=$ Line voltage $(\mathrm{V})$

$\mathrm{I}_{\mathrm{f}}=$ Fault current $(\mathrm{A})$

$\mathrm{Z}=$ Per-unit impedance of the transformer (\%)

$\mathrm{A}=$ Conductor cross-sectional area $\left(\mathrm{mm}^{2}\right)$

$\mathrm{K}=$ Cable factor

$\mathrm{P}=$ Real power $(\mathrm{kW})$

$\mathrm{I}_{\mathrm{L}}=$ Line current $(\mathrm{A})$

$\cos \theta=$ Power factor

$\mathrm{I}=$ Maximum permissible current (A) 
$\mathrm{t}=$ Fault current duration ( $\mathrm{s}$ )

$\mathrm{R}_{\mathrm{n}} \quad=$ Combined earth resistance of $\mathrm{N}$ electrode $(\Omega)$

$\mathrm{R}=$ Resistance of a single electrode $(\Omega)$

$\mathrm{N}=$ Number of electrodes

$\mathrm{F} \quad=$ Factor for multiple earth rods in parallel [15]

\section{Information of case study}

The electrical power engineering department is selected as a case study area and it is situated in Pyay

Technological University in Pyay city at Bago Region in Myanmar. It is constructed with a reinforced concrete, cement one storey building. The size of this building is $(15 \mathrm{~m} \times 9 \mathrm{~m} \times 5 \mathrm{~m})$. The source side of this building is $500 \mathrm{kVA}, 11 / 0.4 \mathrm{kV}$ and power consumption of this building is $37.93 \mathrm{~kW}$ with 0.85 power factor. The current duration is $0.5 \mathrm{~s}$. The TT earthing system is applied in this research.

Firstly, copper rod is used as an electrode from various kinds of earth rod. The copper material is more conductive than other materials except for silver. But copper is cheaper than silver in a practical workplace. Copper rod has strong corrosion resistance, non-cracking and perfect conductive performance. Secondly, the value of resistivity depends on soil nature. To classify the soil types, Standard Penetration Test (SPT) is carried out around this one storey building. From the value of standard penetration test in twelve metre, three samples of soil are measured. They are back filled soil in one meter, a mixture of clay and sand in five meters and sand and sandy in twelve meters. A mixture of clay and sand soil in five meters is chosen because the maximum length of electrode is approximately four metre. Uniform soil pattern is taken into account for earthing system of a building and a supply transformer. From this soil character, the value of soil resistivity, $30 \Omega \mathrm{m}$, is selected to evaluate the earthing resistance. To maintain this soil resistivity, chemical compounds such as charcoal and salt is added to the soil. Numbers of the electrodes and earth mat design is a third and fourth factor for effective earthing system of this building and supply. Multiple earth electrodes are connected in parallel configuration to reduce the value of resistance. For the allocation of multiple electrodes, rectangular shape and triangular shape on numbers of electrodes to form a suitable earth grid design.

In this research, required parameters for earthing system of a transformer and a building are calculated by changing the earthing variables that effect on the earthing resistance. Three conditions based on the above facts are considered to get the lowest earthing resistance for a supply electrical earthing and electrical equipment earthing. Effective diameter, length and spacing of electrodes are evaluated at a uniform soil resistivity. The resulted data are depicted in the following figures and tables [16].

\section{Results and discussions}

For daily life of residences to be safety, electrical installation is very important. Earthing system is one of the most crucial aspects of any electrical installation and essential part of power network to reduce from large electrical disturbances at both low voltage level and high voltage surges. Firstly, sizing of earth cable for a transformer and a building is evaluated from full load current and fault current for both systems that are calculated by using Equation 4, 5, 6 and 7. Cable factor $(\mathrm{K})$ is 115 because of Polyvinyl chloride (PVC) copper cable. The earth conductor size for a transformer is $120 \mathrm{~mm} 2$ from the earth fault current. From current carrying capacities of a building, phase conductor sizes are calculated. According to the minimum cross-sectional area of protective earth conductor in relation to that of an associate phase conductor, $16 \mathrm{~mm} 2$ and $6 \mathrm{~mm} 2$ for a building's installation is determined. This cable is yellow green copper earth cable. Then, earthing resistance for a building is computed by applying the value of soil resistivity, $30 \Omega \mathrm{m}$. The appropriate value of $\lambda$ is taken from factors for parallel electrodes on a number of earth rods. According to Equation 1 , 2 and 3, the value of earthing resistance is computed by varying the diameter of electrode, length of electrode and spacing of adjacent electrodes to achieve the value of resistance that is less than $2 \Omega$.

Three conditions are considered to get an acceptable earthing resistance of a one storey building. Condition $I$ is the changes of diameter of electrode to get an effective diameter of electrode. In Figure 1, resistance is decreased from $1.19 \Omega$ to $1.03 \Omega$ with four rods if the diameter of an electrode increased from $0.0125 \mathrm{~m}$ to $0.1 \mathrm{~m}$. Thus, the diameter of earth rod affects the value of resistance at uniform soil resistivity. Besides, combination of optimal diameter from Condition I and variation of the electrode's length is taken into account in Condition II that is used to gain effective length of electrode. The resistance level and number of electrodes are reduced from $2.31 \Omega$ to $1.69 \Omega$ and four rods to three rods when the length of earth rod increased from $2 \mathrm{~m}$ to $3.75 \mathrm{~m}$ according to Figure 2. To sum up, in Figure 2 , the longer the earth rod, the lesser the resistance can be seen. Changes of space between electrodes linked with Condition II that is provided for 
Condition III. In consequence of this, the value of resistance is minimized from $1.92 \Omega$ to $1.43 \Omega$ at three electrodes with optimal diameter, optimal length and expansion of space from $3.75 \mathrm{~m}$ to $8 \mathrm{~m}$ that is shown in Figure 3. By analysing three conditions, sizing of earth rods impact on the number of electrodes and earth resistance. The spacing between electrode effects on earth resistance value. Changes in earthing resistance depend on the length of the electrode and spacing of adjacent electrodes that are depicted in Figure 2 and Figure 3. By doing this process, optimal diameter, length and spacing between electrodes is produced for the permissible earthing resistance of electrical power engineering department. Firstly, effective diameter and length of electrode from three conditions is applied to evaluate the resistance for a single rod of a supply transformer from Equation 1. Next, maximum permissible current of a single rod is calculated from Equation 8 with the duration of the fault that is assumed to $0.5 \mathrm{~s}$. Equation 9 is used for finding the number of electrodes. And then, earthing resistance on the number of electrodes for a transformer is determined by exploiting Equation 10. The material and type of electrode is solid copper material and vertical earth rod that is applied for corrosion resistance and conductivity.

It can be seen that the level of earthing resistance is obviously decreased to less than $2 \Omega$ by increasing the diameter of earth rod, the length of earth rod and the spacing of earth rod. If it doesn't satisfy, this system is also provided by adding more earth rods and modifying the soil surrounding the electrode with chemical treatment, salt, charcoal and water to reach the desired earth resistance. The minimum earth conductor size of a supply transformer and a building equipment, earthing system is shown in the following Table 1 and Table 2. The relationship of conductor material, fault current and duration of current is illustrated in Table 1.

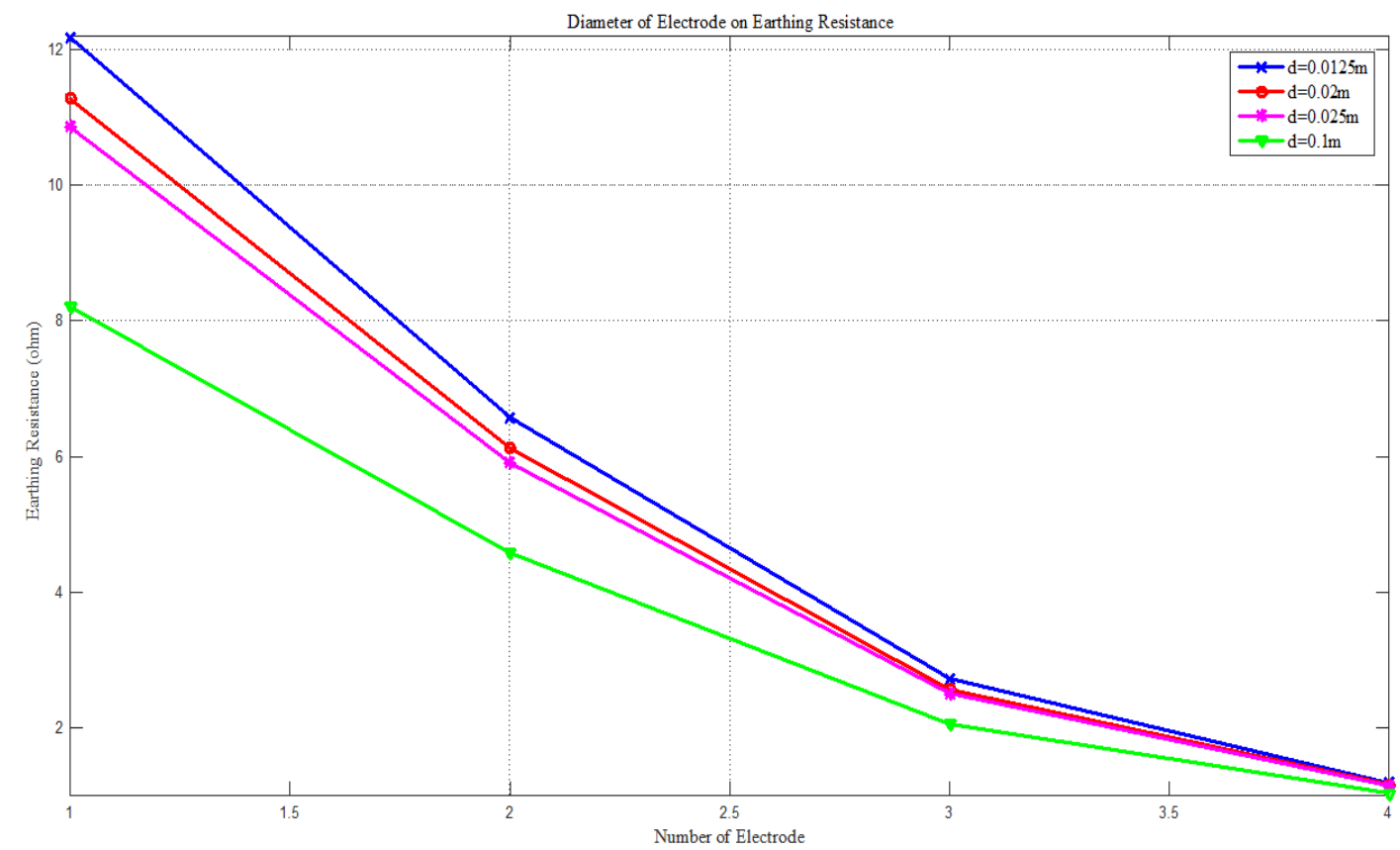

Figure 1 Condition I, variation of electrode diameter on earthing resistance 


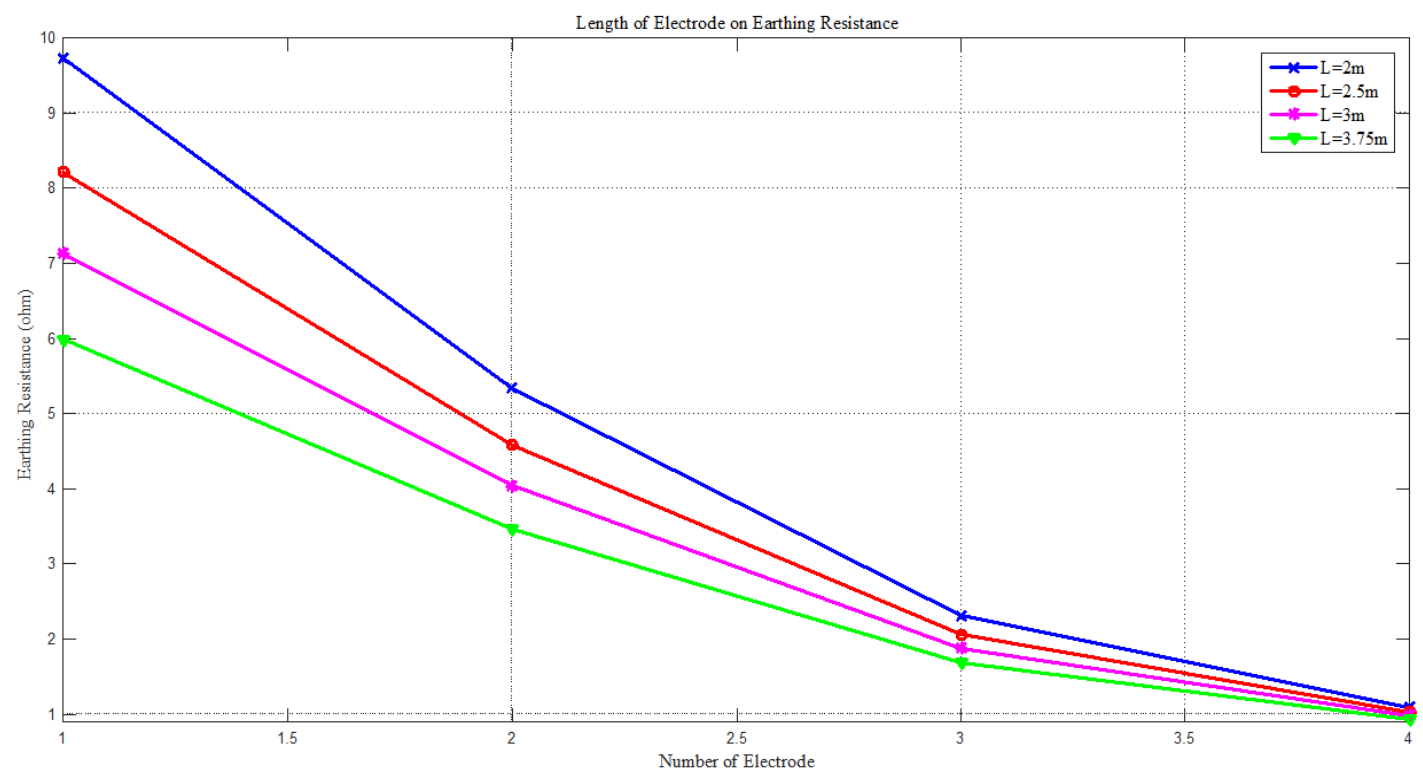

Figure 2 Condition II, variation of electrodes' length of earthing resistance

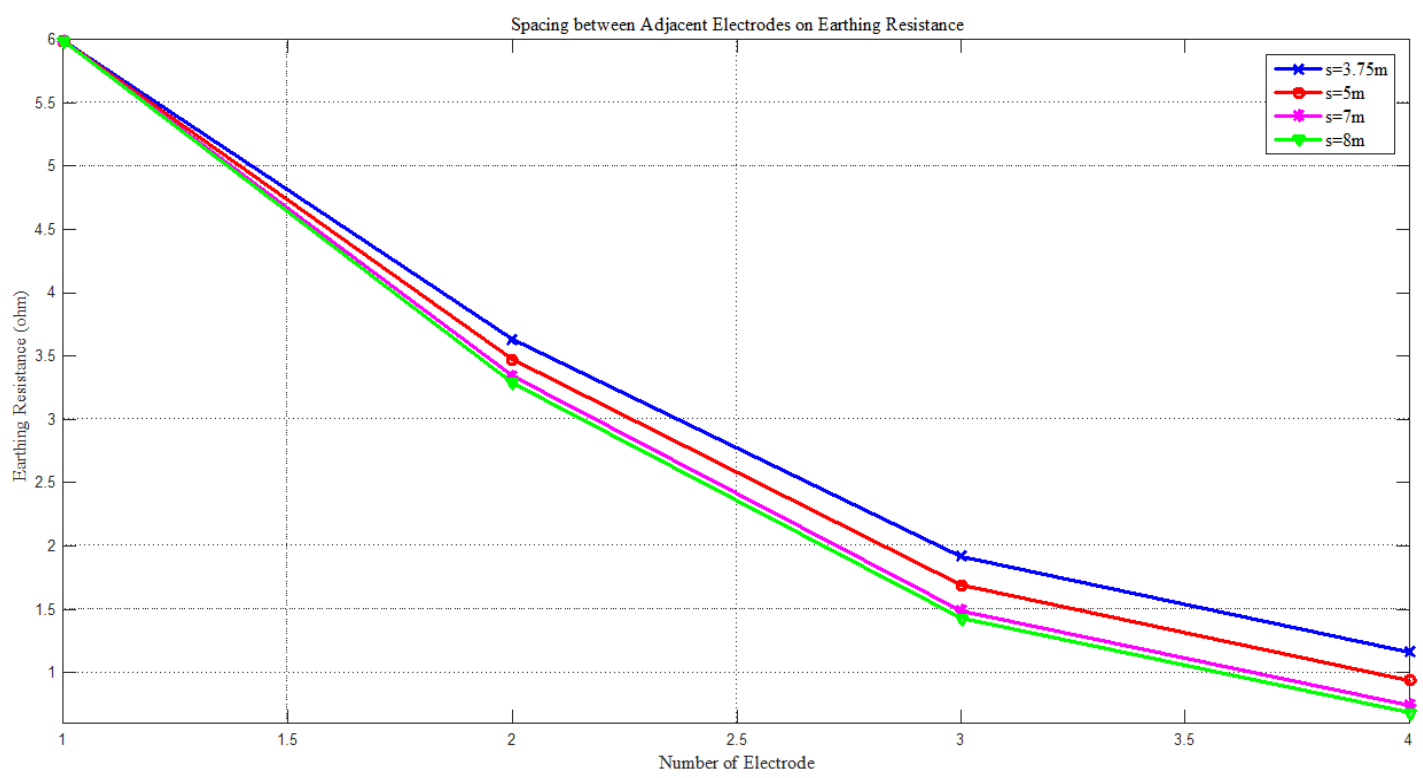

Figure 3 Condition III, variation of electrodes' spacing on earthing resistance

Table 1 Earth conductor size of a supply

\begin{tabular}{|c|c|c|c|c|}
\hline \multirow[t]{2}{*}{$\begin{array}{l}\text { Fault current } \\
\text { (kA) }\end{array}$} & \multicolumn{2}{|c|}{$\begin{array}{l}\text { PVC copper } \\
\left(\mathbf{m m}^{2}\right)\end{array}$} & \multicolumn{2}{|c|}{$\begin{array}{l}\text { XLPE/ copper } \\
\left(\mathbf{m m}^{2}\right)\end{array}$} \\
\hline & $\mathrm{t}=0.5 \mathrm{~s}$ & $t=1 \mathrm{~s}$ & $\mathrm{t}=0.5 \mathrm{~s}$ & $\mathrm{t}=1 \mathrm{~s}$ \\
\hline 18.05 & 120 & 160 & 90 & 130 \\
\hline
\end{tabular}

Table 2 Earth conductor size of equipment

\begin{tabular}{ll}
\hline Current carrying capacity (A) & Yellow green PVC copper $\left(\mathbf{m m}^{2}\right)$ \\
\hline 64 & 16 \\
\hline 37 & 6 \\
\hline
\end{tabular}




\section{Conclusion}

Firstly, the TT earthing system for one storey building and $500 \mathrm{kVA}$, step down transformer is applied in this research. In this system, transformer and building need to be effective earthing system. Good earthing system must be the lowest resistance value. Earthing resistance depends on soil resistivity so the lowest resistivity is chosen. Mixture of clay and soil is selected for a transformer and a building because of the lowest resistivity to calculate the earthing resistance. The load consumptions of electrical engineering department are collected for the conductor sizing. The earth conductor size is 120 $\mathrm{mm} 2$ for a $500 \mathrm{kVA}$ transformer and $16 \mathrm{~mm} 2$ and 6 $\mathrm{mm} 2$ for a building. Copper rod is used as an earth electrode because it is relatively cheap, lack of possible corrosion to fix and can be used to reach into deeper. When it is driven directly into the soil, it can damage the upper copper layer. Thus, the earth pit can make and copper rods put in it. In this earthing system, multiple copper electrodes are used and connected with parallel arrangement. Effective parameters of copper rod are $0.1 \mathrm{~m}$ diameter, $3.75 \mathrm{~m}$ length and $8 \mathrm{~m}$ spacing between rods. By this way, the resulted earthing resistance's value of $1.52 \Omega$ is for a transformer and $1.43 \Omega$ is for a building. These results are within permissible range such as spacing between electrodes is doubled with the length of the electrode. Variation of diameter, length and distance of electrodes is considered in detail to be valid because earth rod must keep in touch with the soil directly. By using an optimal electrode, the number of rods is reduced to three rods in equilateral triangular shape for a building's earthing system and six rods in a rectangular shape for a transformer with an acceptable resistance that is less than $2 \Omega$. So, this system is an effective earthing system of a supply system and electrical equipment because of the lowest resistance to prevent from the risk of electrical hazards.

\section{Acknowledgment}

First of all, the authors are deeply grateful to Dr. Nyunt Soe, Rector of Pyay Technological University, for his kind permission to submit this research work. The authors are much obliged Dr. Soe Winn, Professor and Head of Department of Electrical Power Engineering at Pyay Technological University (PTU), for his useful advice and encouragement during this study. The authors are greatly indebted to their colleagues at the Electrical Power Engineering Department of Pyay Technological University, for their encouragement, good willingness to share ideas, helpful suggestions and support.
Conflicts of interest

The authors have no conflicts of interest to declare.

References

[1] IEEE Industry Applications Society. Power System Technologies Committee. IEEE recommended practice for grounding of industrial and commercial power systems. IEEE; 1982.

[2] Gomez J. Design and calculation of an earth electrode. 2000:79-85.

[3] Oyeleye MO. Evaluation of substation's transformer earthing system, feeder panel and lightning grounding: case study of a university in Nigeria. Evaluation. 2019; 5(9):2805-10.

[4] Kumar V, Kumar N, Chaulya SK, Banerjee G. Earthing system design for electrical installations of building construction and laboratory equipments. International Journal of Scientific Engineering and Research. 2019; 7(4): 26-30.

[5] Oyeleye MO, Makanju TD. Evaluation of steel reinforcement earthing in swamp building. International Journal of Science and Engineering Investigations. 2019; 8(90): 67-73.

[6] Ayodele TR, Ogunjuyigbe AS, Oyewole OE. Comparative assessment of the effect of earthing grid configurations on the earthling system using IEEE and finite element methods. Engineering Science and Technology, an International Journal. 2018; 21(5):970-83.

[7] Michaels K. The equipment grounding system as an effective bonding topology for telecommunications environments. IEEE Transactions on Industry Applications. 2019; 55(6):5605-12.

[8] Talaat M, Farahat MA, Essa MA, Maowwad MS. Simulation of the electric field and the GPR resulting from vertical-driven rods earthing system in a multilayers earth structure. Measurement. 2019; 132:387401.

[9] Mondal D, Dey S, Pradhan AK, Das S. Earthing grid designs for heterogeneous soil structures in hilly regions using current simulation method. IET Generation, Transmission \& Distribution. 2018; 12(12):3021-7.

[10] Wang J, Ni YF, Li Z, Zhang P. An improved method for measuring grounding resistance of transport tower. In international conference on sensor networks and signal processing (SNSP) 2018 (pp. 49-54). IEEE.

[11] Maier V, Pavel SG, Beleiu HG, Pica CS. Optimal design of vertical earth grounding, with rectangular perimeter. In international conference on modern power systems (MPS) 2017 (pp. 1-5). IEEE.

[12] Maier V, Pavel SG, Birou I, Beleiu HG, Ciorca C. Methodologies regarding the application of optimum criteria to the vertical earth grounding design, with rectangular outline. In international conference on electromechanical and power systems (SIELMEN) 2017 (pp. 421-6). IEEE.

[13] Datsios ZG, Mikropoulos PN. Safety performance evaluation of typical grounding configurations of 
MV/LV distribution substations. Electric Power Systems Research. 2017; 150:36-44.

[14] British Standard BS. 7430-1998. Code of practice for Earthing. 1998.

[15] Vijayaraghavan G, Brown M, Barnes M. Practical grounding, bonding, shielding and surge protection. Elsevier; 2004.

[16] Electrical Power Engineering Department. A Department Report. Pyay Technological University, Pyay City, Bago Region, Myanmar, 2018.

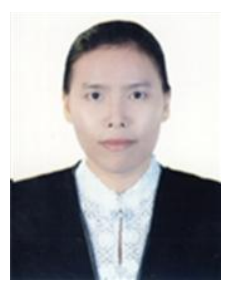

Ms. Su Mon Myint was born in Thongwa Township in Myanmar. Her birth date is 10 April 1984. She got a Doctor of Philosophy from Mandalay Technological University (MTU) in Myanmar. Now, she is working as a Lecturer of Electrical Power Engineering Department at Pyay Technological University (PTU) in Myanmar. She is a member of Myanmar Engineering Society (MES) in Myanmar. She had written the research papers about Loss Reduction, Voltage Profile Improvement, Distribution System Reliability and Fault Analysis.

Email: sumonmyint10@gmail.com

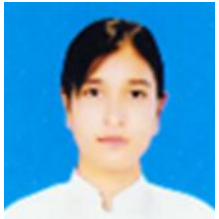

Ms. Khin Thidar Hla was born in Pyay Township in Myanmar. Her birth date is 24 June 1987. She got a Bachelor of Engineering from Pyay Technological University (PTU) in Myanmar. Now, she is working as an Assistant Lecturer of Electrical Power Engineering Department at Pyay Technological University (PTU) in Myanmar.

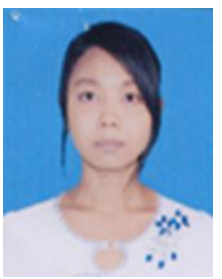

Ms. Theint Theint Tun was born in Pyay Township in Myanmar. Her birth date is 19 January 1990. She got a Bachelor of Engineering from Pyay Technological University (PTU) in Myanmar. Now, she is working as an Assistant Lecturer of Electrical Power Engineering Department at Pyay Technological University (PTU) in Myanmar. 